\title{
Vitamin D Status of Infants in Northeastern Rural Bangladesh: Preliminary Observations and a Review of Potential Determinants
}

\author{
Daniel E. Roth', M. Rashed Shah',2, Robert E. Black', and Abdullah H. Baqui' \\ 'Department of International Health, Johns Hopkins Bloomberg School of Public Health, 615 North Wolfe Street, \\ Baltimore, MD 21205, USA, and 'Projahnmo, Sylhet, Bangladesh
}

\begin{abstract}
Vitamin D deficiency is a global public-health concern, even in tropical regions where the risk of deficiency was previously assumed to be low due to cutaneous vitamin D synthesis stimulated by exposure to sun. Poor vitamin D status, indicated by low serum concentrations of 25 -hydroxyvitamin $\mathrm{D}[25(\mathrm{OH}) \mathrm{D}]$, has been observed in South Asian populations. However, limited information is available on the vitamin D status of young infants in this region. Therefore, to gain preliminary insights into the vitamin $\mathrm{D}$ status of infants in rural Bangladesh, 25(OH)D was assessed in a group of community-sampled control participants in a pneumonia case-control study in rural Sylhet, Bangladesh $\left(25^{\circ} \mathrm{N}\right)$ during the winter dry season (January-February). Among 29 infants aged 1-6 months, the mean 25(OH)D was $36.7 \mathrm{nmol} / \mathrm{L}$ [95\% confidence interval (CI) 30.2-43.2]. The proportion of infants with vitamin D deficiency defined by $25(\mathrm{OH}) \mathrm{D}<25 \mathrm{nmol} / \mathrm{L}$ was $28 \%$ (95\% CI 10-45), 59\% (95\% CI 40-78) had 25(OH)D<40 nmol/L, and all were below $80 \mathrm{nmol} / \mathrm{L}$. From one to six months, there was a positive correlation between age and $25(\mathrm{OH}) \mathrm{D}$ (Spearman $=0.65 ; \mathrm{p}=0.0001$ ). Within a larger group of 74 infants and toddlers aged 1-17 months (cases and controls recruited for the pneumonia study), young age was the only significant risk factor for vitamin D deficiency $[25(\mathrm{OH}) \mathrm{D}<25$ $\mathrm{nmol} / \mathrm{L}]$. Since conservative maternal clothing practices (i.e. veiling) and low frequency of intake of foods from animal source (other than fish) were common among the mothers of the participants, determinants of low maternal-infant 25(OH)D in Bangladesh deserve more detailed consideration in future studies. In conclusion, the vitamin D status in young infants in rural Sylhet, Bangladesh, was poorer than might be expected based on geographic considerations. The causes and consequences of low 25(OH)D in infancy and early childhood in this setting remain to be established.
\end{abstract}

Key words: Risk factors; 25-hydroxyvitamin D; Vitamin D; Vitamin D deficiency; Bangladesh

\section{INTRODUCTION}

Throughout most of the previous century, vitamin $\mathrm{D}$ deficiency and rickets were predominantly perceived as problems of industrialized countries at northern latitudes, where insufficient exposure to sun and intake of vitamin D were linked to inadequate intestinal absorption of calcium and im-

Correspondence and reprint requests should be addressed to:

Dr. Abdullah H. Baqui

Associate Professor

Department of International Health

Bloomberg School of Public Health

Johns Hopkins University

615 North Wolfe Street, Room E8138

Baltimore, MD 21205

USA

Email: abaqui@jhsph.edu

Phone: 410-955-3850 paired skeletal mineralization (1). However, since vitamin $\mathrm{D}$ status has become readily estimable based on serum/plasma 25-hydroxyvitamin D concentration $[25(\mathrm{OH}) \mathrm{D}](2)$, epidemiologic research aimed at identifying previously-uncharacterized at-risk populations and characterizing novel disease associations with vitamin $\mathrm{D}$ status has been greatly facilitated. Thus, vitamin D deficiency has re-emerged as a global public-health concern and is now presumptively linked to a range of infectious, inflammatory and neoplastic diseases throughout the life course and around the world (1).

Low $25(\mathrm{OH}) \mathrm{D}$ is surprisingly common in South Asia, where systemic vitamin $\mathrm{D}$ deficits would be expected to be prevented by cutaneous vitamin $\mathrm{D}$ synthesis stimulated by exposure to sun at relatively low latitudes (3). Few studies on vitamin $\mathrm{D}$ status in infancy have been conducted in South Asia (Table 
1). In Bangladesh, two published reports on childhood $25(\mathrm{OH}) \mathrm{D}$ are available but neither reported 25(OH)D in early infancy (Table 1 ).

Knowledge of the vitamin D status of young children and infants is needed to design studies targeting the aetiologic mechanisms and potential health implications of deficiency. A case-control study on the association between acute lower respiratory tract infection (ALRI) and vitamin D status in infants and young children conducted in Zakiganj subdistrict of Sylhet district in Bangladesh, during January-February 2008, provided an opportunity to gain preliminary insights into the vitamin D status of infants in northeastern rural Bangladesh (4). Here, we aimed to describe the vitamin D status of the source population and briefly review the potential determinants of low infant $25(\mathrm{OH}) \mathrm{D}$ in this setting.

\section{MATERIALS AND METHODS}

\section{Setting}

Zakiganj subdistrict (upazila) is in Sylhet district of northeastern Bangladesh $\left(25^{\circ} \mathrm{N}\right)$, on the border with India. This region has low average household income and maternal literacy and has limited access to healthcare compared to neighbouring subdistricts in Sylhet (5). The study was facilitated by strong existing partnerships with local community organizations, the subdistrict health complex, and the Ministry of Health and Family Welfare, based on an ongoing collaborative neonatal health intervention trial infrastructure (Projahnmo) (6).

\section{Participants}

ALRI cases who met a clinical definition of ALRI were recruited from among infants and young children, aged one month to two years, admitted to the Zakijang subdistrict hospital. Control participants were selected by sampling from among children who lived in the same villages as the cases, were matched to a case on age ( \pm 2 months) and gender, and had no signs of ALRI at recruitment or reported past history of ALRI/pneumonia. To identify controls, a rapid household census was conducted in the village of residence of each case participant to generate a list of eligible controls aged 1-23 months. In an order based on closeness in age to the index case, caregivers of the listed children were approached until a control participant was recruited, consent was obtained, and a blood specimen was collected. If an eligible control was not enrolled, the census and eligible control identification process was repeated in the nearest neighbouring village. Some recruited children not considered eligible for the primary case-control study were included in the present analysis. The major reasons for this difference were that children enrolled during a one-week pilot phase were not included in the case-control study but were included here, and the strict requirement that gross haemolysis be absent on visual inspection of serum specimens included in the case-control study was relaxed for the present analysis. This latter decision was made based on post-hoc findings that the mean $25(\mathrm{OH}) \mathrm{D}$ of grossly haemolyzed specimens was only slightly and non-significantly lower than that of non-haemolyzed serum specimens (difference of means $=3.6 \mathrm{nmol} / \mathrm{L}, \mathrm{p}=0.335$, after adjustment for case-control status).

\section{Collection of data}

Caregivers (mothers) of participants were administered a questionnaire that addressed selected infant, maternal and household characteristics potentially associated with vitamin D status. Maternal intake of foods from animal sources, which included potential sources of vitamin $\mathrm{D}$ and rich sources of calcium, was assessed based on the reported frequency of consumption of food items/categories over the seven days preceding enrollment. Participants were further categorized as to whether the mother had consumed each food item/category at least once in the preceding seven days. Weight of infant was the average of two measurements recorded to the nearest $0.1 \mathrm{~kg}$ (Seca 354 infant scale), and length was the average of two measurements, to the nearest $0.5 \mathrm{~cm}$ (Seca 210 measuring mat). Gender-specific weight-for-age (WA), length-for-age (LA), and body mass index (BMI) z-scores were calculated according to the growth standards of the World Health Organization (7). According to convention, participants with z-score values of less than -2 for each of the anthropometric indices were considered to have stunting (LA), underweight (WA), and low body mass index (BMI). Since reliable information on gestational age at birth was unavailable, anthropometric measures were interpreted under the assumption of term gestation.

A venous blood specimen was collected by standard methods, separated into serum aliquots, and stored at $-20^{\circ} \mathrm{C}$ or less. At the completion of the study, sera were shipped to the laboratory of Dr. Bruce Hollis, Medical University of South Carolina, Charleston, USA, for measurement of the total serum $25(\mathrm{OH}) \mathrm{D}$ concentration by radio-immunoassay (8).

\section{Outcomes}

The primary outcome of the study was the estimated mean $25(\mathrm{OH}) \mathrm{D}$ among infants and children 


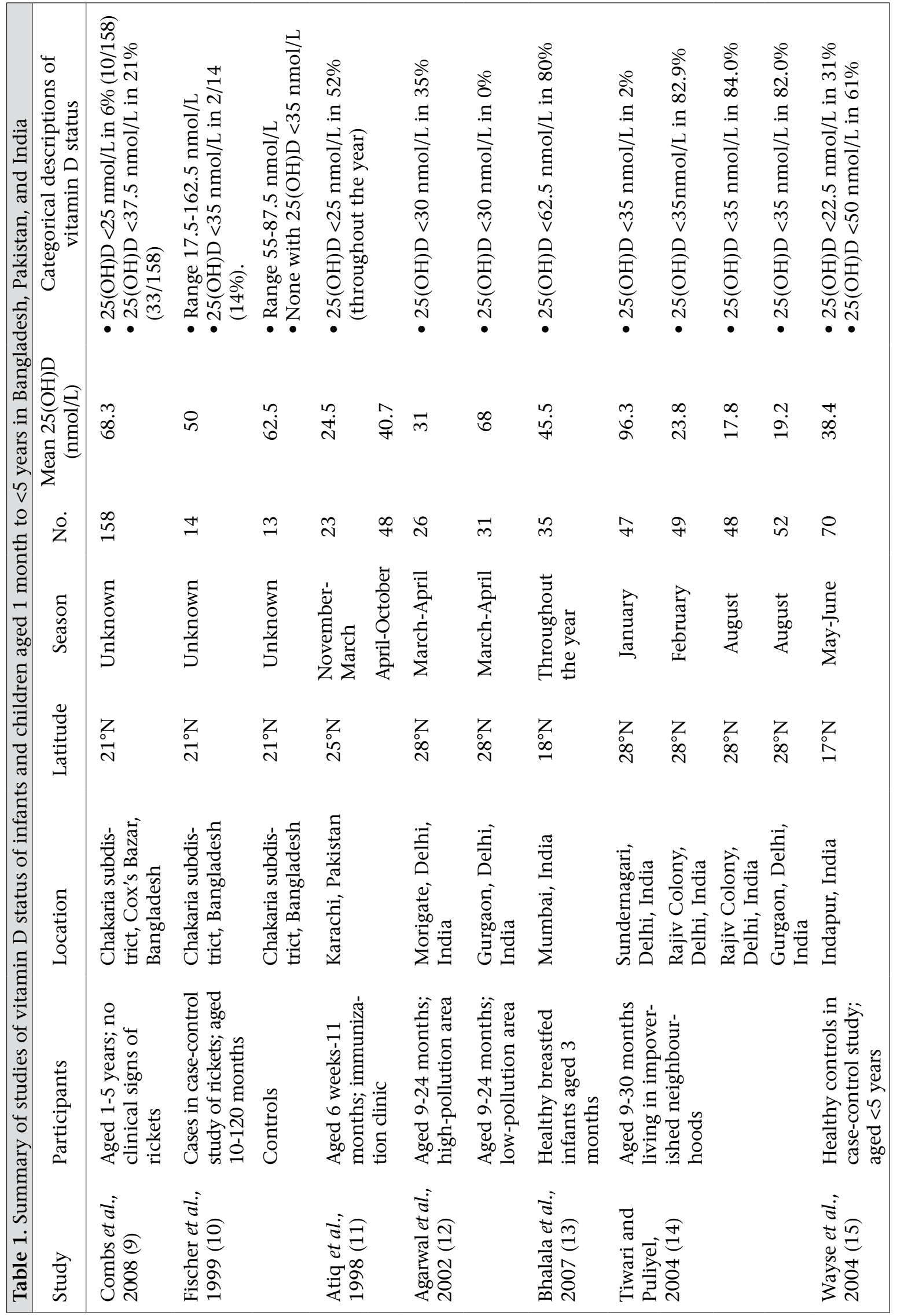


aged one month to two years, in the referral area of Zakiganj subdistrict hospital, based only on the healthy control participants sampled from the community. Since most controls (29/35) from whom blood samples were obtained were aged less than six months, the analysis was focused on this age subgroup. Estimates of the prevalence of vitamin D deficiency were based on the proportion of participants with $25(\mathrm{OH}) \mathrm{D}$ lower than pre-specified cutoffs ( $<25 \mathrm{nmol} / \mathrm{L},<40 \mathrm{nmol} / \mathrm{L}$, and $<80 \mathrm{nmol} / \mathrm{L})$.

As a secondary exploratory analysis, observations relating to infant, maternal or household factors that potentially influenced vitamin D status were drawn from the complete sample of 74 participants (cases and controls) in whom 25(OH)D was measured. Comparisons were made between groups of participants categorized by vitamin D status using a 25-nmol/L cut-off. ALRI cases were included in this analysis to maximize the size of the available sample of infants in whom risk factors could be explored. However, in the primary case-control study, the mean 25(OH)D was significantly lower among ALRI cases compared to controls (4).

\section{Statistical analysis}

The distribution of $25(\mathrm{OH}) \mathrm{D}$ among control participants aged less than six months $(n=29)$ was described by its mean and 95\% confidence interval (CI), standard deviation (SD), median and interquartile range (IQR), and the proportions (and 95\% CIs) of participants with $25(\mathrm{OH}) \mathrm{D}$ less than each of the cut-off values. Other than age and $25(\mathrm{OH}) \mathrm{D}$, which were compared across groups by one-way analysis of variance, the statistical significance of bivariate associations between the vitamin D status and the maternal, infant or household characteristics in the entire sample $(n=74)$ was assessed by non-parametric tests, including chi-square tests, Mann-U Whitney tests, and Spearman's rank correlation coefficient. Given that the determinants of vitamin D status may differ across age-groups, associational analyses were repeated among participants aged less than six months. Analyses were performed using the Stata software (version 10.1) (Stata Corporation, College Station, TX, USA). By convention, the $\mathrm{p}$ values of less than 0.05 were considered significant.

\section{Ethics}

Caregivers provided signed permission before enrollment. The Institutional Review Board of the Johns Hopkins Bloomberg School of Public Health and the ethics committee of the Bangladesh Institute for Child Health at the Dhaka Shishu Hospital, Bangladesh, approved the study.

\section{RESULTS}

\section{Characteristics of study participants}

Serum $25(\mathrm{OH}) \mathrm{D}$ was measured in the 74 participants (39 ALRI cases and 35 controls) during the study. Of 58 potential controls identified in village censuses and approached for participation, 14 were not enrolled due to parental refusal, six due to inability to bring the child to the hospital for study procedures, and three due to history of ALRI. The subgroup of 29 community control participants, aged 1-6 months, consisted mainly of boys (a result of the male predominance among the ALRI cases to whom the controls were sex-matched), with maternal and household characteristics typical of rural Sylhet (Table 2).

\section{Vitamin D status of infants aged | -6 months}

Serum 25(OH)D ranged from 9.5 to $73.9 \mathrm{nmol} / \mathrm{L}$ among the community-sampled infants aged 1-6

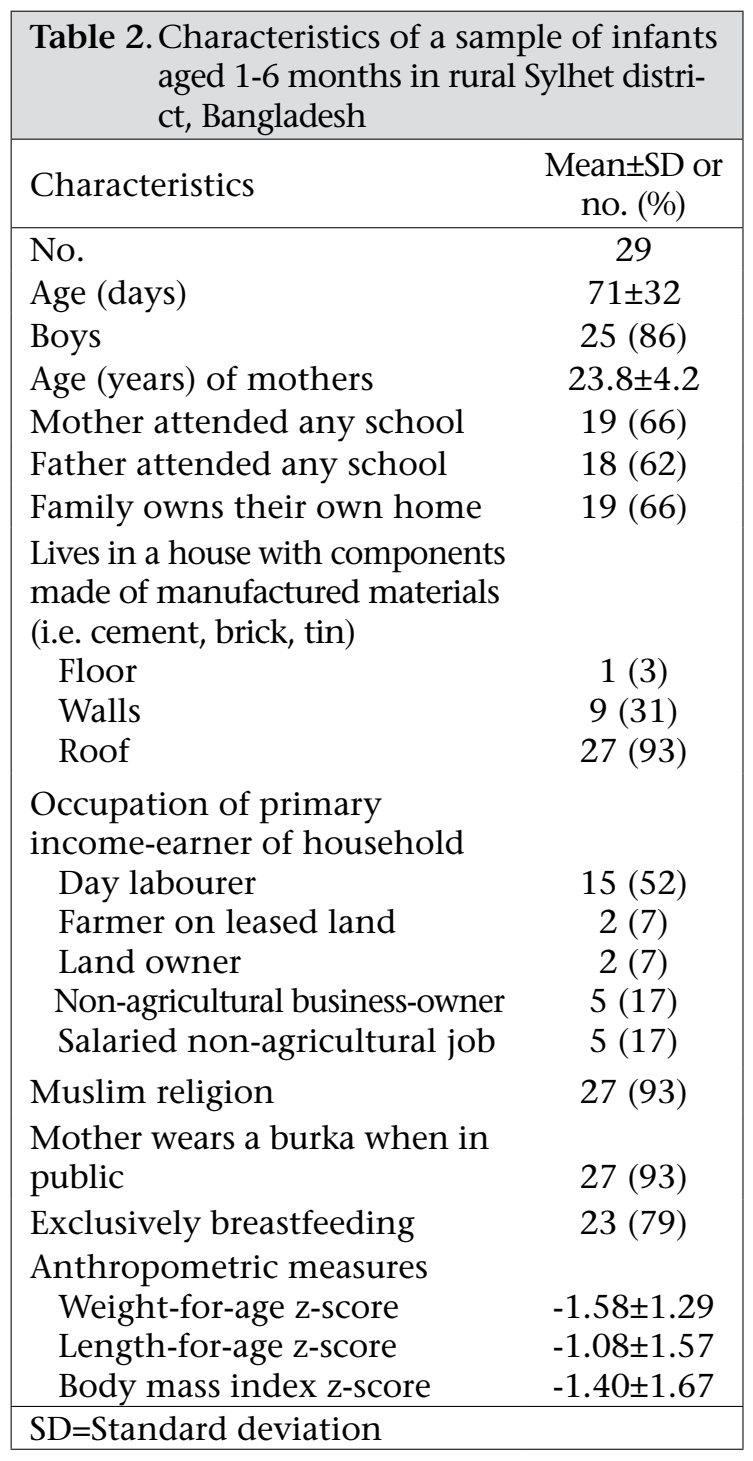


months (Fig.1). Their mean 25(OH)D was 36.7 $\mathrm{nmol} / \mathrm{L}(95 \%$ CI 30.2-43.2; $\mathrm{SD}=17.1 \mathrm{nmol} / \mathrm{L})$, and the median was $38.2 \mathrm{nmol} / \mathrm{L}$ (IQR 25.5). The proportion of infants with $25(\mathrm{OH}) \mathrm{D}$ below each cutoff level was $28 \%(95 \%$ CI $10-45)<25 \mathrm{nmol} / \mathrm{L}$, and $59 \%(95 \%$ CI 40-78) <40 nmol/L; all were below 80 $\mathrm{nmol} / \mathrm{L}$. From one to six months, there was a positive correlation between age and $25(\mathrm{OH}) \mathrm{D}$ (Spearman $\rho=0.65 ; p=0.0001$ ) (Fig.1). Among the youngest 22 infants aged one to less than three months, $36 \%(95 \%$ CI 15-58) had $25(\mathrm{OH}) \mathrm{D}<25 \mathrm{nmol} / \mathrm{L}$, and $73 \%$ (95\% CI 53-93) had 25(OH)D <40 nmol/L.

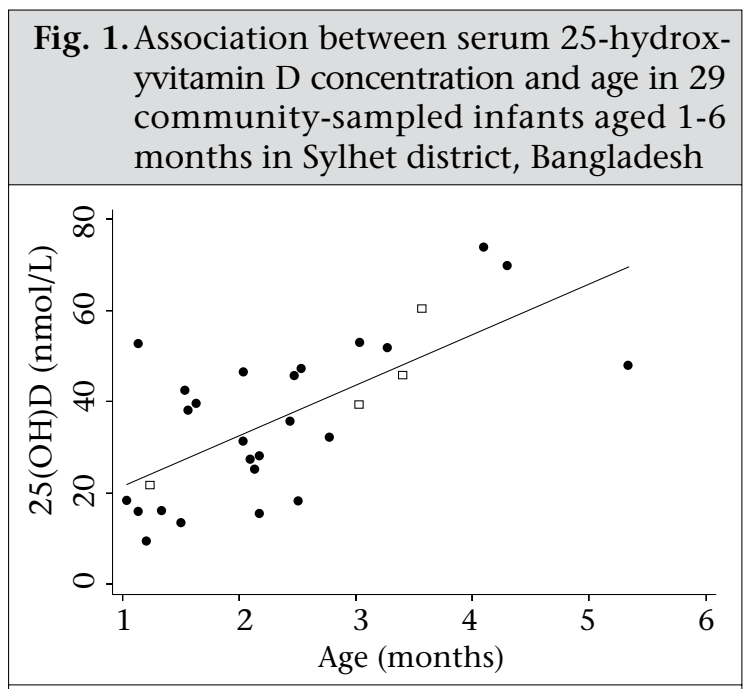

Boys are represented by filled circles and girls by hollow squares; the solid line is a linear leastsquares fit line for boys and girls combined

Characteristics associated with low 25(OH)D

Of the 74 participants (cases and controls) aged 1-17 months, the mean $25(\mathrm{OH}) \mathrm{D}$ was $32.6 \mathrm{nmol} / \mathrm{L}(95 \%$ CI 29.1-36.2), the highest 25(OH)D in any participant was $73.9 \mathrm{nmol} / \mathrm{L}, 24(32 \%)$ had $25(\mathrm{OH}) \mathrm{D}<25$ $\mathrm{nmol} / \mathrm{L}$, and $52(70 \%)$ had $25(\mathrm{OH}) \mathrm{D}<40 \mathrm{nmol} / \mathrm{L}$. In this group, age was the only factor that was significantly associated with vitamin $\mathrm{D}$ deficiency defined by $25(\mathrm{OH}) \mathrm{D}<25 \mathrm{nmol} / \mathrm{L}$ (Table 3$)$. However, deficient infants/toddlers tended to be of lower socioeconomic status based on household ownership and housing materials and were somewhat more likely to be stunted and at low BMI (Table 3). Although there were no significant associations between maternal dietary intake and infant/toddlers' $25(\mathrm{OH}) \mathrm{D}$ (data not shown) or vitamin D deficiency (Table 3), a higher proportion of the mothers of infants with $25(\mathrm{OH}) \mathrm{D} \geq 25 \mathrm{nmol} / \mathrm{L}$ consumed milk, meat, and eggs on at least one occasion during the week preceding the interview (Fig. 2). Results of analyses of associations of vitamin D status with
Fig. 2. Percentage of the study participants whose mothers consumed the specified food item/category at least once during the preceding 7 days, among those participants with $25(\mathrm{OH}) \mathrm{D} \geq 25 \mathrm{nmol} / \mathrm{L}$ (dark bars; $\mathrm{n}=50$ ), and those with $25(\mathrm{OH}) \mathrm{D}<25$ $\mathrm{nmol} / \mathrm{L}$ (light gray bars; $\mathrm{n}=24$ )

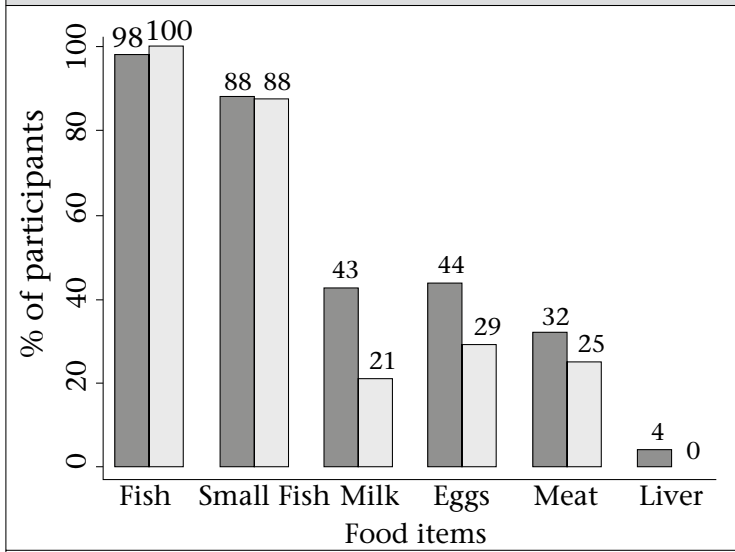

Fish referred to any fish whereas small fish referred to those typically consumed with bones (e.g. mola); meat referred to flesh (i.e. poultry, beef, or mutton)

potential risk factors were similar when repeated in a group restricted to participants aged less than six months (data not shown).

\section{DISCUSSION}

This preliminary study in Sylhet during the winter dry season revealed that the vitamin D status of young infants in rural Bangladesh might be poor enough to put many at risk of rickets and other potential vitamin D-related health consequences. Applying a very conservative definition of vitamin $\mathrm{D}$ deficiency $[25(\mathrm{OH}) \mathrm{D}<25 \mathrm{nmol} / \mathrm{L}]$, we estimated that about one-third of infants aged 1-6 months may be vitamin D-deficient. To our knowledge, this is the first report of vitamin D status in young infants in Bangladesh. However, the causes and consequences of low $25(\mathrm{OH}) \mathrm{D}$ in this setting remain to be determined.

To put these findings in a global context, it is first useful to draw a comparison with what is perhaps the only young infant 'reference' group studied at the equator where vitamin D status would be expected to be optimal throughout the year in the absence of dietary supplementation or fortification. In a sample of infants in Oyem, Gabon $\left(1^{\circ} \mathrm{N}\right)$, the mean 25(OH)D was $110 \mathrm{nmol} / \mathrm{L}$ (SD 43) at birth, $149 \mathrm{nmol} / \mathrm{L}$ (SD 54) at three months of age, and $151 \mathrm{nmol} / \mathrm{L}$ (SD 64) at six months of age (16). These values suggest a very wide variation but that most 


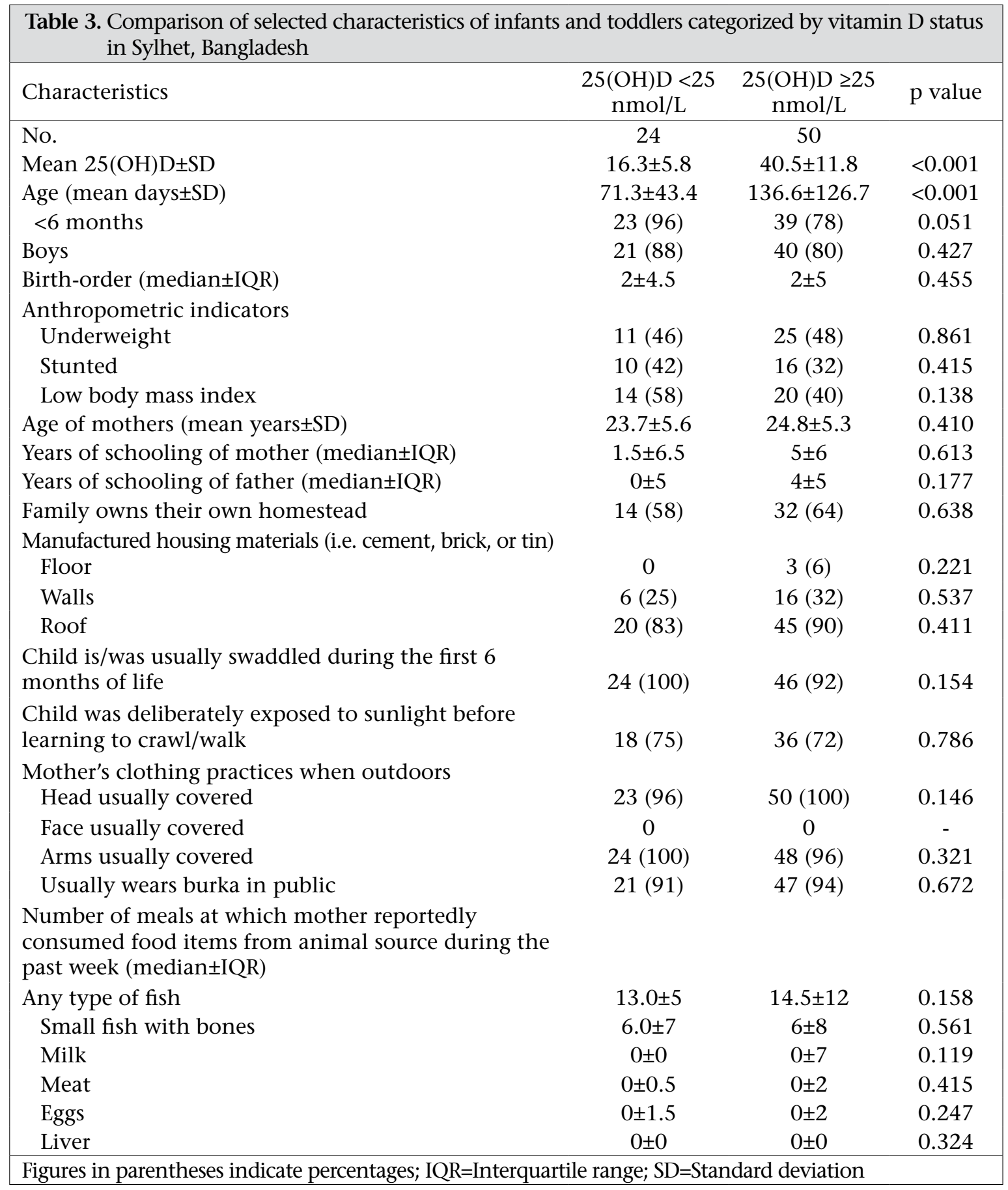

infants in that setting were well above the $25(\mathrm{OH})$ D threshold currently considered optimal ( $>80$ $\mathrm{nmol} / \mathrm{L})(17)$. The present findings from Bangladesh were somewhat intermediary between the results of two other studies in South Asia. In Karachi, Pakistan $\left(25^{\circ} \mathrm{N}\right), 38$ breastfed infants aged less than six months had a mean $25(\mathrm{OH}) \mathrm{D}$ of 25 $\mathrm{nmol} / \mathrm{L}$ (18 SD), and 71\% of infants (12/17) aged less than three months, had $25(\mathrm{OH}) \mathrm{D}<40 \mathrm{nmol} / \mathrm{L}$ (11). Further south, in Mumbai, India $\left(18^{\circ} \mathrm{N}\right)$,
35 breastfed infants at three months of age had a mean 25(OH)D of $49 \mathrm{nmol} / \mathrm{L}$ (SD 24), and 51\% had values of $<37.5 \mathrm{nmol} / \mathrm{L}$ (13). In the United Arab Emirates (UAE), at latitude $24^{\circ} \mathrm{N}$ (about the same as Bangladesh), 78 breastfed term infants aged 1-4 months, born to women with low milk intake and a habitual practice of covering the skin entirely when outdoors, had a median $25(\mathrm{OH}) \mathrm{D}$ of only $11.5 \mathrm{nmol} / \mathrm{L}$, and $82 \%$ had $25(\mathrm{OH}) \mathrm{D}<25$ $\mathrm{nmol} / \mathrm{L}(18)$. 
In Iowa, USA $\left(41^{\circ} \mathrm{N}\right)$, in a longitudinal study of predominantly white infants who were all exclusively breastfed and not receiving supplements, the mean $25(\mathrm{OH}) \mathrm{D}$ at about three and half months of age was $33 \mathrm{nmol} / \mathrm{L}$ for those assessed in the summer $(50 \%$ at $<27.5 \mathrm{nmol} / \mathrm{L})$ and $17 \mathrm{nmol} / \mathrm{L}$ in the winter $(79 \%$ at $<27.5 \mathrm{nmol} / \mathrm{L})$; at approximately six months of age, the mean $25(\mathrm{OH}) \mathrm{D}$ increased to $45 \mathrm{nmol} / \mathrm{L}$ in the summer $(32 \%$ at $<27.5 \mathrm{nmol} / \mathrm{L})$ but remained at $17 \mathrm{nmol} / \mathrm{L}$ for those measured in the winter $(82 \%<27.5 \mathrm{nmol} / \mathrm{L})(19)$. An exogenous vitamin $\mathrm{D}$ source is recommended for all infants in North America. So, it is worthwhile noting that, among formula-fed or vitamin D-supplemented infants (mean vitamin D intake of $\sim 370$ IU per day) aged 1-6 months $(n=37)$ enrolled in a hospital-based study during the winter in Alberta, Canada $\left(53^{\circ} \mathrm{N}\right)$ (20), the mean $25(\mathrm{OH}) \mathrm{D}$ was $78 \mathrm{nmol} / \mathrm{L}$ (Roth D et al. unpublished observations). Although there was a wide variation $(17-152 \mathrm{nmol} / \mathrm{L})$, only one infant aged 1.3 months had $25(\mathrm{OH}) \mathrm{D}<40 \mathrm{nmol} / \mathrm{L}$, demonstrating the real-world effect of supplementation/fortification policies.

Therefore, these data from rural Bangladesh, in combination with earlier findings from infants in urban Pakistan, India, and UAE, have demonstrated that the vitamin D status of young infants in South Asia and the Middle East may be no better than that of unsupplemented infants at much higher northern latitudes in North America, where guidelines support the provision of routine vitamin D supplementation to all breastfed infants $(21,22)$. This implies that a tropical climate does not necessarily protect against low 25(OH)D in early infancy. Although cutaneous pre-vitamin D3 synthesis is expected to occur year-round in South Asia on the basis of latitude (23), there is a substantial seasonal variation in ultraviolet B irradiance (24). In fact, a seasonal differential in vitamin D status was observed among Pakistani infants (11). Therefore, the representativeness of our data is limited because they reflect vitamin D status during the winter, when ultraviolet radiation exposure is at its nadir, and when cutaneous vitamin $\mathrm{D}$ synthesis would be expected to be relatively minimal (24). Moreover, in the Bengal region, the attenuation of actual summer-time ultraviolet radiation exposure due to monsoon cloud-cover (24) may prevent sufficient endowment of vitamin D stores during the summer and, thus, further increase the risk of deficiency during the winter. Our cross-sectional observations suggest that $25(\mathrm{OH}) \mathrm{D}$ in Bangladeshi infants may rise within the first few months of life. However, these age-dependent differences may have been confounded by seasonal timing of ges- tation-a younger age implied that the third trimester coincided with the expected seasonal nadir of vitamin D synthesis, when maternal vitamin D stores might be relatively depleted and, thus, when transfer of vitamin D metabolites to the foetus may have been minimized.

To further explain the apparent 'vitamin D paradox' in South Asia (3), a range of hypothetical mechanisms can be proposed (Table 3). Young infants depend almost entirely on the transplacental transfer of vitamin $\mathrm{D}$ and $25(\mathrm{OH}) \mathrm{D}$, which explains the consistent association between maternal and cord-blood $25(\mathrm{OH}) \mathrm{D}(25)$ and the observation that maternal antenatal vitamin $\mathrm{D}$ supplementation augments both maternal and cord-blood $25(\mathrm{OH}) \mathrm{D}$ (26). Therefore, the major reason that Bangladeshi infants start life with poor vitamin D stores is low maternal antenatal $25(\mathrm{OH}) \mathrm{D}$, which has been documented in urban and rural Bangladeshi women of reproductive age (27). Islam et al. recently studied female workers in a garment factory in Dhaka and speculated that their long day-time hours in indoors, brief exposure to low-intensity sunlight in the early morning, outdoor air pollution, and widespread sunscreen use, in combination with darklypigmented skin, may contribute to their poor vitamin D status (mean $25(\mathrm{OH}) \mathrm{D}$ of $37 \mathrm{nmol} / \mathrm{L}$, and $15 \%$ of the participants had $25(\mathrm{OH}) \mathrm{D}<25 \mathrm{nmol} / \mathrm{L})$ (28). Conservative dress, including almost complete skin coverage by traditional veils or cloaks, has been emphasized as a contributor to vitamin $\mathrm{D}$ deficits in Muslim women in South Asia and the Middle East because it limits cutaneous vitamin D synthesis regardless of the intensity of ambient ultraviolet B (29).

Inferences regarding the determinants of infant/ toddlers' vitamin D status in this study were limited, largely because of the small sample-size and substantial uniformity with respect to selected maternal clothing and dietary practices. We also acknowledge that pooling of ALRI cases and controls to maximize our available sample-size may have led to selection biases. However, the observation that mothers of infants with relatively low $25(\mathrm{OH}) \mathrm{D}$ seemed less likely to consume foods from animal sources (other than fish) deserves consideration in future studies. The amount of vitamin $\mathrm{D}$ in the local diet is unknown but low calcium intake (or reduced absorption of calcium due to high phytate intake), typical of low-income diets in Bangladesh $(30,31)$, may accelerate $25(\mathrm{OH}) \mathrm{D}$ use, leading to relativelyincreased vitamin D demands (32). Since the concentration of vitamin D metabolites in breastmilk is determined by maternal vitamin $\mathrm{D}$ status, maternal vitamin $\mathrm{D}$ deficiency during lactation may 


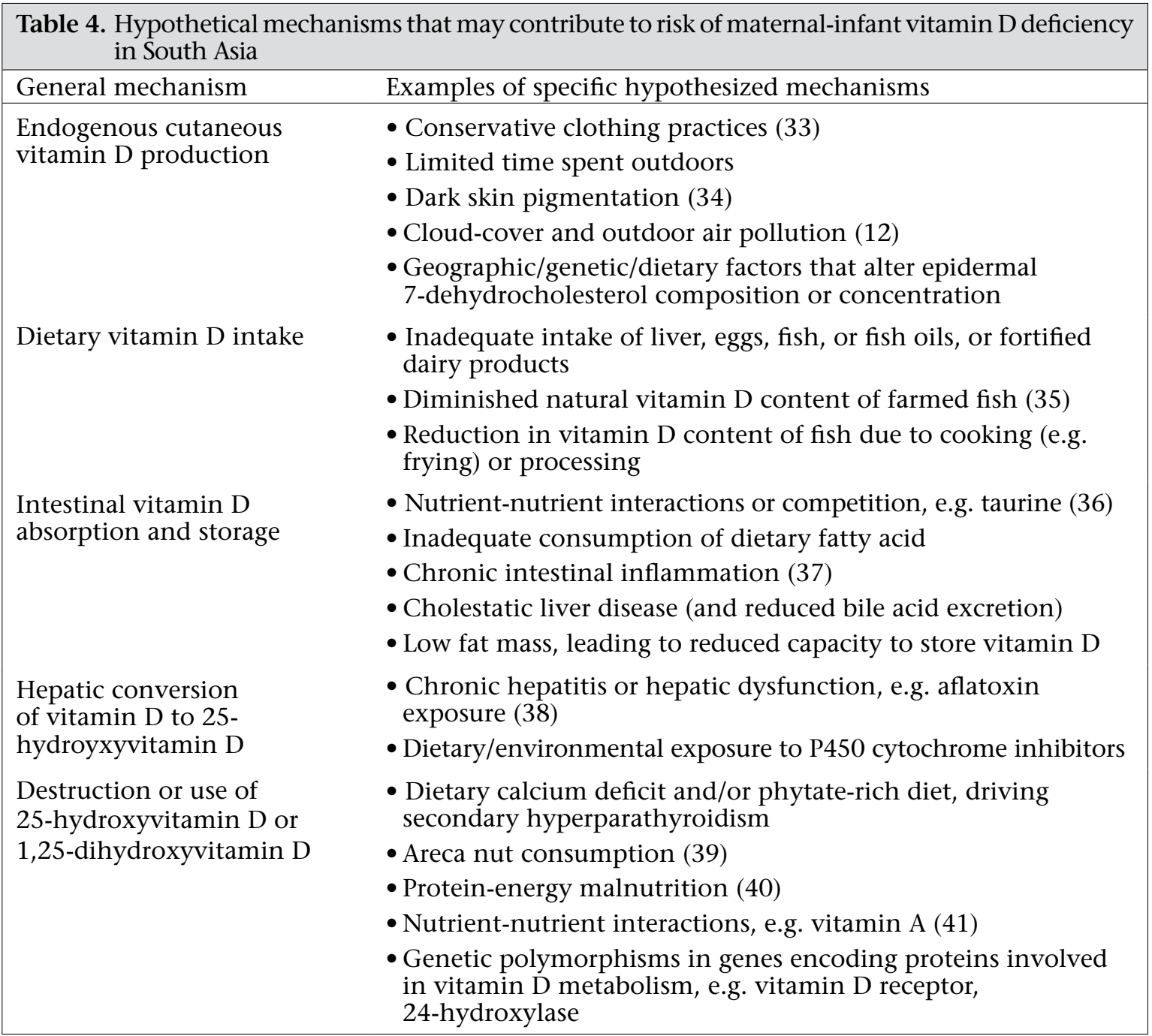

cause ongoing deficits in postnatal infants' vitamin D intake (42); yet, maternal factors cannot entirely account for the persistence of low 25(OH)D among toddlers (Table 1) who experience direct exposure to sun and should be unaffected by the conservative clothing practices of their mothers. Therefore, much remains to be learnt about the determinants of vitamin D status throughout infancy and childhood, particularly where $25(\mathrm{OH}) \mathrm{D}$ appears discrepant from that which would be expected based on latitude.

Despite the current enthusiasm for vitamin D supplementation in the USA (22), the effects of vitamin D deficits during early infancy are still not fully understood, and meaningful inflection points in 25(OH)D-outcome relationships have not been established. The most widely-accepted manifestation of severe vitamin D deficiency in infancy is rickets, the classical childhood metabolic bone disease associated with skeletal hypomineralization and deformities, muscle weakness, and growth impair- ment (1). Young infants with severe congenital vitamin D deficiency may present with hypocalcaemic tetany or seizures, with absent or subtle skeletal pathology (43-45). Greer noted that there is no clear or consistent association between $25(\mathrm{OH}) \mathrm{D}$ and the risk of rickets or other functional outcomes (46). Although $25(\mathrm{OH}) \mathrm{D}<25 \mathrm{nmol} / \mathrm{L}$ is typical of clinically-apparent rickets, early stages of the disease may occur at higher $25(\mathrm{OH}) \mathrm{D}(\sim 40 \mathrm{nmol} / \mathrm{L})$ (47), with declines in $25(\mathrm{OH}) \mathrm{D}$ occurring as the disease progresses and vitamin $\mathrm{D}$ stores are depleted. The frequent occurrence of $25(\mathrm{OH}) \mathrm{D}>25 \mathrm{nmol} / \mathrm{L}$ among toddlers and older children with rickets has been presumptively attributed to dietary calcium deficits (48); however, rickets among breastfed infants with $25(\mathrm{OH}) \mathrm{D}>25 \mathrm{nmol} / \mathrm{L}$ (49) suggests that factors other than calcium intake may be implicated.

In Bangladesh, rickets may be more common than previously thought, based on surveys of lower limb 
deformities in ambulating children $(50,51)$. Recent data from a nationwide survey suggest that about $0.6 \%$ of Bangladeshi children, aged 1-15 years, may have radiologic evidence of rickets, with the highest prevalence in Chittagong and Sylhet divisions (51). The incidence of symptomatic hypocalcaemia secondary to vitamin D deficiency in early infancy is unknown. Some investigators have played down the role of vitamin D in rickets in Bangladesh (10, 52 ), instead blaming dietary calcium deficits or other mineral deficiencies or excesses, e.g. aluminum (53). However, in case-control studies, dietary calcium intake between rickets-affected and unaffected households did not differ (54) whereas the mean 25(OH)D in cases was significantly lower than in controls (10). A plausible hypothesis is that vitamin D deficiency acts synergistically with other causes of inadequate bone mineralization and that an individual's $25(\mathrm{OH}) \mathrm{D}$ concentration below which clinical signs emerge depends on the severity and multiplicity of other genetic and environmental factors.

Beyond rickets, speculation abounds regarding the potential extra-skeletal consequences of suboptimal vitamin D status during foetal development and infancy. The vitamin D receptor has been found within virtually every organ-system (55), and the active metabolite of vitamin $\mathrm{D}$ is well-described as a potent mediator of cell proliferation and differentiation, particularly noted for its range of effects on immune function in laboratory models (56). The case-control study for which the data for the present analysis were primarily collected revealed an inverse association between $25(\mathrm{OH}) \mathrm{D}$ and the odds of hospitalization for ALRI (4), corroborating the findings in neonates in Turkey (57) and children in India (15). If vitamin D deficiency is confirmed as a risk factor for pneumonia, interventions to improve maternal-infant vitamin D status could reduce the global burden of ALRI, the single most important cause of early childhood death in the world (58). Other postulated consequences of antenatal or infant vitamin D deficiency include growth faltering $(59,60)$, type 1 diabetes $(61)$, and asthma (62). However, rigorous studies of the broad health benefits of interventions to improve the antenatal or postnatal vitamin D status in South Asian mothers and infants have yet to be reported.

\section{Limitations}

This study was limited by its small sample-size, restricted geographic scope, and cross-sectional design. We aimed to select control participants for the main case-control study in a manner that would enable inferences about the source population. Selection of control was necessarily non-random from the perspective of age and gender and, thus, unfortunately led to an over-representation of boys; however, there is unlikely to be a gender differential in vitamin D status during early infancy (63). Also, the requirement for an absence of reported history of ALRI probably produced negligible bias since only three otherwise eligible children were excluded for this reason. Aside from these caveats, the community-based sampling was likely random with respect to most determinants of vitamin $D$ status. The group of infants aged 1-6 months was small but adequate to estimate the mean $25(\mathrm{OH}) \mathrm{D}$ within a 13-nmol/L range with 95\% confidence. However, data were insufficient to yield precise estimates of the associations between infant and maternal characteristics and 25(OH)D. Another limitation was the lack of ancillary biochemical or radiographic data that may have revealed evidence of adverse consequences of low 25(OH)D. We did not report the findings of physical examinations because scoring systems for rickets are not very useful in early infancy, and a protocol for a standardized musculoskeletal clinical examination was not satisfactorily implemented. However, none of the toddlers had any clinical evidence of rickets according to the physician's examination (data not shown).

\section{Conclusions}

This study provides initial observations on the vitamin D status of young infants in northeastern rural Bangladesh. However, it remains to be determined whether the relatively left-shifted distribution of $25(\mathrm{OH}) \mathrm{D}$ in this study sample is representative of the broader population and causally associated with an excess burden of rickets, symptomatic hypocalcaemia, growth faltering, or extra-skeletal health outcomes. Therefore, recommendations for universal antenatal and/or infant vitamin D supplementation in Bangladesh based on biochemical data alone would be premature. The causes and consequences of low $25(\mathrm{OH}) \mathrm{D}$ in young infants in South Asia must be further investigated.

\section{ACKNOWLEDGEMENTS}

The authors thank the participants and caregivers for their kind cooperation and also thank the study field staff, the Projahnmo Sylhet team, and personnel at the Zakiganj subdistrict hospital. They particularly thank Kazi Moksedur Rahman (Deputy Executive Director, SHIMANTIK), Dr. Arun Kumar Roy (Project Research Physician, Projahnmo), Dr. Daniel Hossain (Project Research Manager, Projah- 
nmo), Dr. Sirajul Islam (Upazila Health and Family Planning Officer), and Dr. Jonme Joy Dutta Shankar (Medical Officer, Zakiganj subdistrict hospital). The authors are grateful to Dr. Bruce Hollis and Dr. Carole Wagner (Medical University of South Carolina, USA), Dr. Samir K. Saha (Bangladesh Institute of Child Health, Dhaka Shishu Hospital, Dhaka, Bangladesh), and the Department of International Health at the Johns Hopkins Bloomberg School of Public Health. D. Roth was supported by training grants from the Canadian Institutes for Health Research and the Alberta Heritage Foundation for Medical Research.

\section{REFERENCES}

1. Holick MF. Resurrection of vitamin D deficiency and rickets. J Clin Invest 2006;116:2062-72.

2. Zerwekh JE. Blood biomarkers of vitamin D status. Am J Clin Nutr 2008;87:1087S-91S.

3. Joshi SR. Vitamin D paradox in plenty sunshine in rural India-an emerging threat. J Assoc Physicians India 2008;56:749-52.

4. Roth DE, Shah R, Black RE, Baqui AH. Vitamin D status and acute lower respiratory infection in early childhood in Sylhet, Bangladesh. Acta Paediatr 2010;99:389-93.

5. Baqui, AH, Arifeen SE, Darmstadt GL, Ahmed S, Seraji HR, Winch PJ et al.; Bangladesh Projahnmo Study Group. Differentials in neonatal mortality in two adjacent rural areas of Bangladesh: lessons for neonatal health interventions. Global Public Health 2008;3:366-82.

6. Baqui AH, Arifeen SE, Darmstadt GL, Ahmed S, Williams EK, Seraji HR et al. Effect of community-based newborn-care intervention package implemented through two service-delivery strategies in Sylhet district, Bangladesh: a cluster-randomised controlled trial. Lancet 2008;371:1936-44.

7. WorldHealth Organization. WHOchildgrowthstandards:length/height-for-age, weight-for-age, weigh$\mathrm{t}$-for-length, weight-for-height and body mass indexfor-age: methods and development. Geneva: World Health Organization, 2006. 312 p.

8. Hollis BW, Kamerud JQ, Selvaag SR, Lorenz JD, Napoli JL. Determination of vitamin D status by radioimmunoassay with a 125I-labeled tracer. Clin Chem 1993;39:529-33.

9. Combs GF, Jr., Hassan N, Dellagana N, Staab D, Fischer P, Hunt $\mathrm{C}$ et al. Apparent efficacy of foodbased calcium supplementation in preventing rickets in Bangladesh. Biol Trace Elem Res 2008;121:193-204.

10. Fischer PR, Rahman A, Cimma JP, Kyaw-Myint TO, Kabir AR, Talukder K et al. Nutritional rickets with- out vitamin D deficiency in Bangladesh. J Trop Pediatr 1999;45:291-3.

11. Atiq M, Suria A, Nizami SQ, Ahmed I. Maternal vitamin-D deficiency in Pakistan. Acta Obstet Gynecol Scand 1998;77:970-3.

12. Agarwal KS, Mughal MZ, Upadhyay P, Berry JL, Mawer EB, Puliyel JM. The impact of atmospheric pollution on vitamin $\mathrm{D}$ status of infants and toddlers in Delhi, India. Arch Dis Child 2002;87:111-3.

13. Bhalala U, Desai M, Parekh P, Mokal R, Chheda B. Subclinical hypovitaminosis D among exclusively breastfed young infants. Indian Pediatr 2007;44:897901.

14. Tiwari L, Puliyel JM. Vitamin D level in slum children of Delhi. Indian Pediatr 2004;41:1076-7.

15. Wayse V, Yousafzai A, Mogale K, Filteau S. Association of subclinical vitamin D deficiency with severe acute lower respiratory infection in Indian children under 5 y. Eur J Clin Nutr 2004;58:563-7.

16. Nguema-Asseko B, Ganga-Zandzou PS, Ovono F, Lendoye E, Lemamy GJ, Akendengue B et al. [Vitamin D status in Gabonese children]. Arch Pediatr 2005;12:1587-90 [French].

17. Heaney RP. Vitamin D: criteria for safety and efficacy. Nutr Rev 2008;66(10 Suppl 2):S178-81.

18. Dawodu A, Agarwal M, Hossain M, Kochiyil J, Zayed R. Hypovitaminosis D and vitamin D deficiency in exclusively breast-feeding infants and their mothers in summer: a justification for vitamin $D$ supplementation of breast-feeding infants. J Pediatr 2003;142:16973.

19. Ziegler EE, Hollis BW, Nelson SE, Jeter JM. Vitamin $D$ deficiency in breastfed infants in Iowa. Pediatrics 2006;118:603-10.

20. Roth DE, Jones AB, Prosser C, Robinson JL, Vohra S. Vitamin D status is not associated with the risk of hospitalization for acute bronchiolitis in early childhood. Eur J Clin Nutr 2009;63:297-9.

21. Canadian Paediatric Society. Vitamin D supplementation: recommendations for Canadian mothers and infants. Paediatr Child Health 2007;12:583-98.

22. Wagner CL, Greer FR; American Academy of Pediatrics Section on Breastfeeding; American Academy of Pediatrics Committee on Nutrition. Prevention of rickets and vitamin D deficiency in infants, children, and adolescents. Pediatrics 2008;122:1142-52.

23. Holick MF. Environmental factors that influence the cutaneous production of vitamin D. Am J Clin Nutr 1995;61(3 Suppl):638S-645S.

24. Bachelet D, Barnes PW, Brown D, Brown M. Latitudinal and seasonal variation in calculated ultraviolet- $\mathrm{B}$ irradiance for rice-growing regions of Asia. Photochem Photobiol 1991;54:411-22. 
25. Hollis BW, Pittard WB, 3rd. Evaluation of the total fetomaternal vitamin D relationships at term: evidence for racial differences. J Clin Endocrinol Metab 1984;59:652-7.

26. Specker B. Vitamin D requirements during pregnancy. Am J Clin Nutr 2004;80(6 Suppl):1740S-7S.

27. Islam MZ, Lamberg-Allardt C, Kärkkäinen M, Outila T, Salamatullah Q, Shamim AA. Vitamin D deficiency: a concern in premenopausal Bangladeshi women of two socio-economic groups in rural and urban region. Eur J Clin Nutr 2002;56:51-6.

28. Islam MZ, Shamim AA, Kemi V, Nevanlinna A, Akhtaruzzaman M, Laaksonen $\mathrm{M}$ et al. Vitamin $\mathrm{D}$ deficiency and low bone status in adult female garment factory workers in Bangladesh. Br J Nutr 2008;99:1322-9.

29. Dawodu A, Absood G, Patel M, Agarwal M, Ezimokhai $\mathrm{M}$, Abdulrazzaq $\mathrm{Y}$ et al. Biosocial factors affecting vitamin D status of women of childbearing age in the United Arab Emirates. J Biosoc Sci 1998;30:431-7.

30. Islam MZ, Lamberg-Allardt C, Kärkkäinen M, Ali SM. Dietary calcium intake in premenopausal Bangladeshi women: do socio-economic or physiological factors play a role? Eur J Clin Nutr 2003;57:674-80.

31. Hels O, Hassan N, Tetens I, Haraksingh Thilsted S. Food consumption, energy and nutrient intake and nutritional status in rural Bangladesh: changes from 1981-1982 to 1995-96. Eur J Clin Nutr 2003;57:58694.

32. Clements MR, Johnson L, Fraser DR. A new mechanism for induced vitamin $\mathrm{D}$ deficiency in calcium deprivation. Nature 1987;325:62-5.

33. Matsuoka LY, Wortsman J, Dannenberg MJ, Hollis BW, Lu Z, Holick MF. Clothing prevents ultraviolet-B radiation-dependent photosynthesis of vitamin D3. J Clin Endocrinol Metab 1992;75:1099-103.

34. Clemens TL, Adams JS, Henderson SL, Holick MF. Increased skin pigment reduces the capacity of skin to synthesise vitamin D3. Lancet 1982;1:74-6.

35. Lu Z, Chen TC, Zhang A, Persons KS, Kohn N, Berkowitz R et al. An evaluation of the vitamin D3 content in fish: is the vitamin D content adequate to satisfy the dietary requirement for vitamin D? J Steroid Biochem Mol Biol 2007;103:642-4.

36. Zamboni G, Piemonte G, Bolner A, Antoniazzi F, Dall'Agnola A, Messner $\mathrm{H}$ et al. Influence of dietary taurine on vitamin D absorption. Acta Paediatr 1993;82:811-5.

37. Leichtmann GA, Bengoa JM, Bolt MJ, Sitrin MD. Intestinal absorption of cholecalciferol and 25-hydroxycholecalciferol in patients with both Crohn's disease and intestinal resection. Am J Clin Nutr 1991;54:54852.
38. Glahn RP, Beers KW, Bottje WG, Wideman RF, Jr., Huff WE, Thomas W. Aflatoxicosis alters avian renal function, calcium, and vitamin D metabolism. J Toxicol Environ Health 1991;34:309-21.

39. Ogunkolade WB, Boucher BJ, Bustin SA, Burrin JM, Noonan K, Mannan N et al. Vitamin D metabolism in peripheral blood mononuclear cells is influenced by chewing "betel nut" (Areca catechu) and vitamin D status. J Clin Endocrinol Metab 2006;91:2612-7.

40. Fraser DR. Vitamin D-deficiency in Asia. J Steroid Biochem Mol Biol 2004;89-90:491-5.

41. Allegretto EA, Shevde N, Zou A, Howell SR, Boehm $\mathrm{MF}$, Hollis BW et al. Retinoid $\mathrm{X}$ receptor acts as a hormone receptor in vivo to induce a key metabolic enzyme for 1,25-dihydroxyvitamin D3. J Biol Chem 1995;270:23906-9.

42. Hollis BW, Wagner CL. Assessment of dietary vitamin $\mathrm{D}$ requirements during pregnancy and lactation. Am J Clin Nutr 2004;79:717-26.

43. Ahmed I, Atiq M, Iqbal J, Khurshid M, Whittaker P. Vitamin D deficiency rickets in breast-fed infants presenting with hypocalcaemic seizures. Acta Paediatr 1995;84:941-2.

44. Hatun S, Ozkan B, Orbak Z, Doneray H, Cizmecioglu F, Toprak D et al. Vitamin D deficiency in early infancy. J Nutr 2005; 135:279-82.

45. Balasubramanian S, Shivbalan S, Kumar PS. Hypocalcemia due to vitamin D deficiency in exclusively breastfed infants. Indian Pediatr 2006;43:247-51.

46. Greer FR. 25-Hydroxyvitamin D: functional outcomes in infants and young children. Am J Clin Nutr 2008;88:529S-33S.

47. Arnaud SB, Stickler GB, Haworth JC. Serum 25hydroxyvitamin D in infantile rickets. Pediatrics 1976;57:221-5.

48. DeLucia MC, Mitnick ME, Carpenter TO. Nutritional rickets with normal circulating 25-hydroxyvitamin D: a call for reexamining the role of dietary calcium intake in North American infants. J Clin Endocrinol Metab 2003;88:3539-45.

49. Kreiter SR, Schwartz RP, Kirkman HN, Jr., Charlton PA, Calikoglu AS, Davenport ML. Nutritional rickets in African American breast-fed infants. J Pediatr 2000;137:153-7.

50. Hellen Keller International. Rickets in Bangladeshi children: a small focus or a widespread problem?. Dhaka: Hellen Keller International, 2001. 4 p. (Nutrition surveillance bulletin no. 4).

51. International Centre for Diarrhoeal Disease Research, Bangladesh. National rickets survey in Bangladesh, 2008. Health Sci Bull 2009;7:7-11.

52. Craviari T, Pettifor JM, Thacher TD, Meisner C, Ar- 
naud J, Fischer PR; Rickets Convergence Group. Rickets: an overview and future directions, with special reference to Bangladesh. A summary of the Rickets Convergence Group meeting, Dhaka, 26-27 January 2006. J Health Popul Nutr 2008;26:112-21.

53. Cimma JP, Arnaud J, Labarere J, Guillard O, Nugues F, Marrauld A et al. Effect of consumption of food cooked in aluminium or stainless-steel pots on Bangladeshi children with calcium-deficient rickets: an eight month trial. J Trace Elem Med Biol 2004;17:24953.

54. Combs GF, Hassan N. The Chakaria food system study: household-level, case-control study to identify risk factor for rickets in Bangladesh. Eur J Clin Nutr 2005;59:1291-301.

55. Norman AW. From vitamin D to hormone D: fundamentals of the vitamin D endocrine system essential for good health. Am J Clin Nutr 2008;88:491S-9S.

56. van Etten E, Stoffels K, Gysemans C, Mathieu C, Overbergh L. Regulation of vitamin D homeostasis: implications for the immune system. Nutr Rev 2008;66(10 Suppl 2):S125-34.

57. Karatekin G, Kaya A, Salihoğlu O, Balci H, Nuhoğlu A. Association of subclinical vitamin $\mathrm{D}$ deficiency in newborns with acute lower respiratory infection and their mothers. Eur J Clin Nutr 2009;63:473-7.

58. Black RE, Cousens S, Johnson HL, Lawn JE, Rudan I, Bassani DG et al. Global, regional, and national causes of child mortality in 2008: a systematic analysis. Lancet 2010;375:1969-87.

59. Brooke OG, Butters F, Wood C. Intrauterine vitamin D nutrition and postnatal growth in Asian infants. $\mathrm{Br}$ Med J (Clin Res Ed) 1981;283:1024.

60. Rajah J, Jubeh JA, Haq A, Shalash A, Parsons H. Nutritional rickets and $\mathrm{z}$ scores for height in the United Arab Emirates: to D or not to D? Pediatr Int 2008;50:424-8.

61. Zipitis CS, Akobeng AK. Vitamin D supplementation in early childhood and risk of type 1 diabetes: a systematic review and meta-analysis. Arch Dis Child 2008;93:512-7.

62. Camargo CA, Jr., Rifas-Shiman SL, Litonjua AA, RichEdwards JW, Weiss ST, Gold DR et al. Maternal intake of vitamin D during pregnancy and risk of recurrent wheeze in children at $3 \mathrm{y}$ of age. Am J Clin Nutr 2007;85:788-95.

63. Gordon CM, Feldman HA, Sinclair L, Williams AL, Kleinman PK, Perez-Rossello J et al. Prevalence of vitamin D deficiency among healthy infants and toddlers. Arch Pediatr Adolesc Med 2008;162:505-12. 